\title{
BUILDING COALITIONS: Communication/Developing Members
}

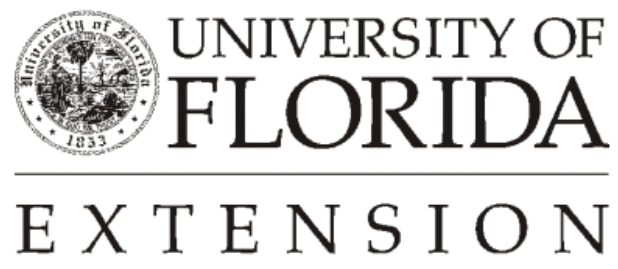

Institute of $\mathbf{F}_{\text {ood and }} \mathbf{A}_{\text {gricultural }} \mathbf{S}_{\text {ciences }}$ 
The coalition has been selected and is ready to begin addressing the challenges that lie ahead. To be effective and efficient, the members need to understand important group processes. Using these will help the group work together and do more.

When people gather as group, they may not act in the same way as when they are alone or with one other person. Each group develops its own pattern of interaction as it goes through various phases, as members become comfortable, learning to know and trust one another. As trust develops at least four things should happen:

1. The group should develop valuable facilitation skills.

2. The group should develop cohesiveness.

3. The group should use an effective decision-making process.

4. The group should exhibit critical thinking.

\section{Group Facilitation Skills}

Forming a group requires teamwork, perseverance, cooperation and imagination. The group's facilitator and members each have unique responsibilities to help make the coalition successful and to meet its goals.

\section{Facilitator Functions}

- $\quad$ Relieve the anxiety of members about being with unknown members.

- Develop an agenda. This will allow each coalition member to know what is to be done.

- $\quad$ Have an agenda for each meeting. Share with members before the meetings.

- Do not allow yourself to become the focus.

- Do not allow one member to dominate the discussions.

- $\quad$ Encourage silent members.

- $\quad$ Halt side conversations.

- Help the group to stay on the topic. 


\section{Facilitator /Member Functions}

- Initiate new ideas, goals and procedures.

- Share the responsibility of seeking information and opinions.

- Clarify what others have said, when appropriate, by adding examples, illustrations or explanations.

- Explain the relationship among facts, ideas and suggestions of two or more group members.

- $\quad$ Support group members though praise and agreement. Tell others they agree with what is being proposed if they do.

- Mediate differences between others and bring about collaboration from conflict.

- Be certain that all have an equal chance to be heard.

\section{Group Cohesiveness}

Having a good facilitator and willing members form a coalition does not imply they have a cohesive group. It may appear the group members like each other and seem to get along. However, cohesive characteristics come with time, as the group works together. In Group Process, Joseph Luft suggests four criteria have to be met before a set of individuals can be considered a group.

- Interaction takes place among members.

- Members share a common purpose or goal.

- A differentiation of jobs emerges.

- The value of being a part of the group is greater to the individual than being separate.

The group must develop a strong feeling of "we-ness," a member talking in terms of "we" rather than "I." "We" team members:

- Display loyalty and congeniality to each other.

- Work together for a common goal. 
- $\quad$ Take responsibility for group tasks.

- $\quad$ Endure pain and frustration for the group.

- $\quad$ Defends against criticism and attack.

Trust is the most important ingredient to developing a cohesive group. The first crisis most groups face involves the ability of members to trust themselves and each other. Trust will reduce members' fear of acceptance and support. It involves everyone's self-disclosure.

\section{Increasing Group Cohesiveness}

Factors that increase group cohesiveness:

1. All members complete worthwhile tasks and feel they are appreciated by the group.

2. Members clearly perceive the group goals and consider them to be realistic.

3. Members perceive the group as an entity in its own right, calling it "the group" or "our group."

4. The group has prestige.

5. Members possess knowledge or material needed by the group.

6. Members perceive the issues at hand to be of importance.

7. Personal interaction among members is based on equality, with no one exercising much authority over anyone else.

8. Members are not jealous and competitive with one another.

Source: Holli, B.B., and Calabrese, R.J. (1991) Communication and Education Skills (2nd ed.). Philadelphia: Lee and Febiger.

\section{The Decision-Making Process}

Every group makes decisions. Groups that make effective decisions usually use a decision-making process. They select alternative solutions and chart a course of action. The way a group makes a decision influences how members feel about the group. It also can determine how well the group members support the decision. Steps in group decision-making are: 
1. Define the problem.

2. Decide a method for making the decision.

3. Gather information.

4. List possible alternative solutions.

5. Develop lists of pros and cons for alternatives.

6. Decide an alternative solution and carry it out.

7. Evaluate.

\section{Define the Problem}

The problem should be written clearly so all group members know and understand it. Larger problems should be divided into sub-problems. This will allow for better understanding among group members, thus, finding a successful solution.

\section{Decide on a Method}

There are different methods to arrive at a decision. They include consensus, voting and the leader deciding. Let's look at some advantages and disadvantages of each method.

Consensus is the synthesis of ideas. When alternatives are discussed, the group hears the views of all the members and discusses the issue until it is felt everyone agrees. A vote is not taken, but the facilitator gives any member the chance to object. If there is objection from any one member the group must continue to look for an alternative. Advantages to this system include:

1. Cooperative decision-making, since all members have a hand in the decision.

2. Provides for a "win-win" solution.

3. Facilitates open communication.

4. Requires all members to listen and understand all sides.

5. Sets the stage for an action plan. 
Disadvantages to consensus decision-making are:

1. It takes a large amount of time. The larger the group the more time it takes.

2. Some group members may not want to speak out if the trust level is low.

3. The leader must play a facilitating role. Some leaders are not willing to share the control.

Voting is another acceptable method. After the information has been gathered and alternatives listed, the group decides which will be the best way to solve the problem. The idea behind the system is that though the majority rules, the minority must go with the decision. The main advantage is this method requires less time to make a decision. However, members who were on the losing (minority) side may not feel committed to the decisions. They may not wholeheartedly help to accomplish the task.

Letting the leader decide is a method that would only be used in extreme cases when time does not allow input from other group members. Even if a leader is unable to meet with the group, he or she should contact some members of the group for their ideas. This method takes members completely out of the decision-making process and, thus, the group commitment level will be extremely low.

\section{Gather Information}

Information on the problem should be shared. The more that is known, the more productive the discussion of alternatives will be. All members should be allowed to add specific information to the pool of information.

\section{List Possible Alternatives and Solutions}

Members should list all the possible solutions to the problem. This is not the place to limit thinking! List responses so none are forgotten.

\section{List Pros and Cons}

For each solution, list the pros and cons. Consider all implications of each alternative. This will provide direction as the group moves closer to deciding on just one solution.

\section{Decide On An Alternative}

This is the point of deciding which alternative is the best solution and will move the group ahead. Remember all members need to have a stake in the decision and a part in the plan of action. 


\section{Evaluate}

Once a decision has been made, it is essential that the group have an evaluation system in place. Much can be learned and applied to future decision-making.

The way a group feels after making a decision is important, especially if the group plans to have a continuing positive relationship. High levels of harmony are noted by positive feelings, a high percentage of membership participation and shared decision-making.

\section{Critical Thinking}

Critical thinking is:

- The ability to see that problems have multiple solutions.

- An alternative to making decisions by blind acceptance, impulse or whim, tradition or habit.

- A process, not an outcome.

- A method of exploring and imagining alternatives.

- A process used to develop and evaluate positions on issues.

- An essential element of problem solving, decision-making and creativity.

- A total approach to understanding how we make sense of a work that includes many parts, not simply one way of thinking.

\section{Principles of Critical Thinking}

1. A learning environment must provide the opportunity for adults to consider the strengths and weaknesses of opposing views.

2. Evaluate a wide range of alternatives when making decisions.

3. The atmosphere of the learning environment should be one of collaborative inquiry by the members.

4. The learning environment must reflect probing questions by the members.

5. Adult learners should engage in exploratory dialogue with themselves or others, proposing ideas and translating subject matter insights and evidence into reflective thought. 
6. Members identify implications of actions.

7. A learning environment in which generalizations are challenged facilitates critical thinking. (Jones 1989)

Am I a critical thinker? For each pair listed below, which one best describes your actions as a coalition team member?

\section{A Critical Thinker}

Goes through a problem.

Says, "Let's find out."

Listens.

Says, "There ought to be a better way."

Takes a big problem and separates it into smaller, easier to manipulate, parts

Focuses.

Learns from mistakes.

Accepts the viewpoints of others.

Recognizes the limits of knowledge
and is sensitive to bias and prejudice

Recognizes the limits of knowledge
and is sensitive to bias and prejudice.

\section{A Non-Critical Thinker}

- Goes around it, and never get past it.

- $\quad$ Says, "Nobody knows."

- Waits until it's their turn to talk.

- $\quad$ Says, "That's the way it's always been done."

- $\quad$ Takes many little problems and rolls them together until they are unsolvable.

- Does not concentrate on the problem.

- Only learns not to make mistakes by not trying anything new.

- Unable or unwilling to consider others' points of view.

- $\quad$ Afraid to say, "I don't know." 


\section{References}

Barker, L.L., R.J. Kibler, K.J. Wahlers and K. W. Watson. Groups in Process: Small Group Communication. 3d ed. New Jersey: Prentice Hall, 1987.

Bull, N., and J. Jones. "Are We Fostering Critical Thinking in Our Adult Learners?" Unpublished manuscript, The Ohio State University.

Holli, B.B. and R.J. Calabrese. Communication and Education Skills. 2d ed. Philadelphia: Lee and Febiger,1991.

\section{Authors}

Jeffrey King, Assistant Professor, Assistant Staff Development Specialist, The Ohio Cooperative Extension Service, The Ohio State University .

Kathryn Beckham, Assistant Professor, Family Life Specialist, The Ohio Cooperative Extension Service, The Ohio State University.

\section{(C)1992 The Ohio State University}

This series on Coalition Building was developed by The Ohio Center For Action on Coalition Development for Family and High Risk Youth, Richard Clark, Ph.D., Director. It has been adapted for County Extension Faculty in Florida to facilitate work with local and regional organizations and groups such as non-profits, cooperatives, county extension associations, and others that might benefit from a plan for working together to achieve support for mutual goals.

This document is FY498, Part 6 of the 16 part series adapted for use in Florida by Elizabeth B. Bolton, Professor, Community Development and Lisa Guion, Assistant Professor, Program Planning and Evaluation; Department of Family, Youth and Community Sciences, Florida Cooperative Extension Service, Institute of Food and Agricultural Sciences, University of Florida, Gainesville, 32611-0310.

Reprinted with permission March, 1997. Revised April, 2002.

The Institute of Food and Agricultural Sciences is an equal opportunity/affirmative action employer authorized to provide research, educational information and other services only to individuals and institutions that function without regard to race, color, sex, age, handicap, or national origin. For information on obtaining other extension publications, contact your county Cooperative Extension Service office. 